\title{
Mitigating Underinvestment Through an IT-Enabled Organization Form
}

\author{
Barrie R. Nault \\ Graduate School of Management, University of California at Irvine, Irvine, California 92717
}

\begin{abstract}
$\mathrm{T}$ he highly readable essay nicely, and rigorously, illustrates how information technology (IT) can enable a new form of the horizontal networked organization through the provision of appropriate incentives to key actors within franchise arrangements. What is novel about the approach taken is that while it is well known that IT-enhanced control systems can improve monitoring, it is less well understood how IT can improve incentive structures.
\end{abstract}

Robert Zmud

\begin{abstract}
Information technology (IT) enables a new refinement of the horizontal network organization. We show that IT can be applied to a hybrid form of market and hierarchy, franchising, and demonstrate how the resulting horizontal network organization can be an improved organization form. Specifically, we use IT-enabled "ownership of customers" to refine the horizontal network organization and show how that refinement can alleviate the problem of franchise underinvestment in traditional franchising. In traditional franchising each franchise underinvests relative to investments in an integrated firm because the benefits that accrue to other franchises from its investment (horizontal externalities) are not accounted for in its investment decision. Ownership of customers is a combination of identifying individual customers with individual franchises, monitoring customer transactions across franchises, and transferring benefits between franchises based on those transactions. Because ownership of customers rewards franchises for the beneficial horizontal externalities generated by their investments, the levels of investment that are chosen by franchises may be increased, although not to the levels that would occur in an integrated firm. As long as IT costs are covered, the franchisor is always more profitable and, if necessary, the franchisor and franchisees can be jointly more profitable. Consequently, if profits can be redistributed in lump-sum form, then the franchisor and franchisees can be individually more profitable. The analysis applies to all horizontal organizations where ownership of customers is feasible and where there are sufficient transactions between units for ownership of customers to be worthwhile.

(Network Organizations; Franchising; Organization Design; Horizontal Externalities)
\end{abstract}

\section{Introduction}

The rise to prominence of the network organizational form in the last two decades is well-known and welldocumented (e.g., Snow et al., 1992, p. 20.) The network organization has been viewed as a series of interrelationships with several possible topologies, all based on the grouping together of different activities along the value chain. The focus on different value chain activities is consistent with the view of hierarchies as vertically integrated operations, and a partition of those operations naturally decomposes into vertically related activities. Thus, network organizations are seen as vertical combinations of brokers, designers, marketers and distributors, producers and suppliers (Miles and Snow 1992). Horizontally integrated firms and hybrid organizational forms with a horizontal orientation, such as franchising and sharecropping, are less well-known as network organizations. Thorelli (1986) describes, for example, mutually interdependent franchises with linkages between them as a network. In a different context, Rogers (1983) uses horizontal networks to describe decentralized diffusion organized through clients or users at local units, and the corporation of the 1990s is viewed as a networking organization with virtual horizontal and vertical working patterns (Scott-Morton 1991).

This article refines the horizontal network organization, examining relationships between units operating at the same level in a market channel rather than on relationships along the value chain. We define a horizontal network organization as an organizational form

1047-7039/97/0803/0223/\$05.00 
characterized by a single central authority and many members that each have local knowledge and operate at the same level in a market channel. Our refinement is that interdependencies between members are accounted for through the incentive structure. We explore how information technology (IT) enables that refinement of the horizontal network organization through the implementation of a system of monitoring and incentives we call ownership of customers (OoC). Formulating a model by abstracting from a case example of IT in franchising, we show how the refined horizontal network organization can improve the profitability of the franchisor and, in some cases, of the franchisees.

The choice of an organizational form for a dispersed operation with many locations involves a horizontal agency problem: Each outlet or franchise ignores the effects of its actions on other outlets or franchises (Katz 1989). That is, unless the incentives reward actions based on external as well as internal effects, external effects will not be accounted for in local decision making. A commonly used example of that problem is advertising spillovers. Local advertising by a particular outlet or franchise may produce positive benefits to other outlets or franchises situated nearby. First, the advertising may reach nonlocal customers. Second, and the object of our analysis, customers that receive the advertising locally may purchase elsewhere. Unless explicitly included in the incentive structure, the local outlet or franchise does not include those benefits, or horizontal externalities, in its advertising decision. Of course, the horizontal agency problem exists because local information and activity is not contractible and therefore the franchisor cannot mandate local actions. Otherwise, the franchisor, accounting for those externalities, would specify all the actions the franchisees must undertake in a contract. Typically, horizontal externalities are not included in the franchise's incentive structure because it is difficult to measure those externalities perfectly. Moreover, tying the externalities to individual franchise actions, which would be necessary to provide proper incentives, is even more difficult.

Empirical studies in economics have established that principal-agent and information problems are the dominant explanations why firms choose franchising as an organizational form. Results from Brickley and Dark (1987), for example, support the hypothesis that the choice between franchising and an integrated firm with multiple outlets reflects tradeoffs among agency problems. Furthermore, Norton (1988) found significant positive relationships between the incidence of fran- chising and principal-agent incentives, and between the incidence of franchising and informational incentives. In other words, there is clear evidence that the choice of franchising as an organizational form is preferred when agency problems are significant.

We demonstrate that IT-enabled $\mathrm{OoC}$ is a partial solution to the horizontal agency problem whereby local actions affect the purchases of local customers elsewhere. OoC has three features supported by IT: (a) unique identification of individual customers with individual franchises, (b) perfect monitoring of customer purchases across franchises, and (c) transfers of profits between franchises based on customer purchases between franchises. That is, each customer is owned by one franchise, all purchases are tracked perfectly across the network of franchises by the franchisor, and profits from between-franchise purchases are transferred between those franchises. In our formulation the customer pays the owning franchise and that franchise makes a transfer to the serving franchise, although which franchise is paid and which receives the transfer does not affect the nature of our results. IT is the necessary enabler of the OoC-refined organizational form: a database matching customers to franchises, network-wide transaction processing, and a form of electronic funds transfer.

We examine the impact of changes in incentives due to $\mathrm{OoC}$ on one aspect of individual franchise investment and on the profitability of our refinement of the horizontal network organization. The new organizational form can alleviate the franchisee underinvestment that is present in traditional franchising. We find that if franchisees are more profitable under OoC than under the next best alternative, for example, joining a different franchising organization or other business opportunity, then, as long as IT costs are covered, the franchisor is always more profitable and, if necessary, the franchisor and franchisees can always be made jointly more profitable by increasing investments by all franchisees. Alternately, if profits can be redistributed to the franchisees in lump-sum form through some sort of fixed payment, then as long as IT costs are covered the franchisor is always more profitable, the franchisor and franchisees can be jointly more profitable, and the franchisees can be individually more profitable. Thus, our refinement of the horizontal network organization is sufficiently flexible to support increased profitability with a variety of objectives.

In franchise operations, decision (investment) rights are divided between the franchisor and franchisees based on a franchise contract. Typically, there are two aspects of investments in franchise operations: (a) local 
investments by individual franchisees and (b) national investment by the franchisor. Local investments are made independent of the franchisor because they require local expertise and the costs of such investment are borne by the franchisee. National investment is funded from the royalty and the franchise fee and is controlled by the franchisor. There is often an information asymmetry between the franchisor and the franchisee: The franchisee knows the relationship between local investments and demands, where as the franchisor may not. That asymmetry is based on local knowledge and expertise, knowledge and expertise that applies to customers in the franchise territory. Thus, we examine one aspect of investment, investment that affects only those customers that are associated with a given franchise's territory. ${ }^{1}$

Our idea of OoC is best illustrated through a wellknown case: Pacific Pride Systems (HBS Case Services 1985, 1986, 1988; Nault and Dexter 1992, 1995). Pacific Pride Systems is a network of commercial fueling station franchises. Customers purchase fuel from automated stations that operate similarly to automated teller machines. The franchises have a form of closed territory distribution, that is, exclusive rights to customers based within a territory (Mathewson and Winter 1984). Those exclusive rights have two aspects. First, only one franchise is permitted in a specific geographical area-for example, a zip code. Second, and more importantly, the franchise has exclusive rights to customers residing in the territory. Although customers may purchase fuel away from their home territory, they are identified in Pacific Pride's database as being owned by their home franchise. In fact, through the use of IT, the home franchise bills the customer (i.e., the customer pays the home, or owning, franchise) and then makes a transfer to the serving franchises for customer purchases away from the home territory. Because the franchises are part of a network, when away from their home location, customers prefer to purchase from franchises that are on the network, mostly because it gives them greater control over their commercial driving fleet. Using one network means the customer receives a single itemized bill, and special computerized card access limits the problem of allowing drivers discretion over fuel purchases.

The Pacific Pride case is not unique, nor is the model applicable only to franchise structures. Our model of organization form can be implemented in cases where the following conditions hold.

- There is a single central authority and many members.
- The central authority can collect a royalty for goods or services.

- Transfers between members of all or part of a profit margin are possible.

- Ownership of each and every individual customer can be uniquely established.

- For each customer transaction the identities of the owner and server of the customer can be verified.

Another important case is partnership arrangements used in multiple-location professional service firms that serve multidivisional clients across different geographical areas. As we discuss in the conclusion, there is also potential for OoC to enable virtual horizontal networks between different organizations. There are cases in which it is not profitable to apply $\mathrm{OoC}$, and those are discussed in the conclusion as well.

After outlining the franchise structure we employ and specifying the demands faced by each franchise, we describe the impact of $\mathrm{OoC}$ on franchise investment. A comparison is drawn between investments in our refinement of the horizontal network organization, investments in traditional franchising, and investments in a fully informed integrated firm. We then compare the profitability of OoC with traditional franchising. Finally we summarize the analyses and consider other cases where OoC has been implemented and where the refined horizontal network organization is possible.

\section{Franchise Structure}

The franchise structure we model has one franchisor and many franchises. Franchises are assigned territories and have exclusive rights to customers associated with the territory. Customers have demands both inside and outside their territory. Territories do not overlap. Each franchisee maximizes profit by selecting its level of investment-for example, investment in customer recruitment. Under traditional franchising the franchisor maximizes profit by choosing the margin received by the franchise per unit sold by the franchise. Under IT-enabled OoC the franchisor also chooses the transfer per unit between franchises for purchases by a customer from one franchise in the territory of another franchise. For our analysis of franchise investment, we abstract from other issues of vertical control and contracts in franchise organizations, the most prominent of which is lump-sum franchise fees. Lump-sum franchise fees do not affect marginal investment, thus they do not impact the analysis of franchise investment. Redistribution of profits through lump-sum payments becomes important in our analysis of organization form 
profits. Choice of the margin by the franchisor is equivalent to selecting any combination of unit royalty, unit cost, and retail price. For example, for a given unit cost set by the franchisor to the franchise, retail price maintenance would be equivalent to setting the margin.

Individual franchises are identified by the variable $x$, which can represent any given attribute. Thus, franchises differ in the dimension represented by $x$. For example, $x$ could represent an index of the size of the franchise territory population. We use $x$ to build a continuous distribution of potential franchise attribute values, $f(x)$, between the smallest and largest $x$, allowing for more than one franchise with a given attribute value. Thus, $f(x)$ is positive over the range of $x$ and is zero elsewhere. That is not a strong assumption as we can scale $x$ as needed to make the range continuous. Let investment by franchise $x$ be represented by $e_{x}$ where investment amounts range over the interval $\left[e_{x}, \overline{e_{x}}\right]$. Then $\underline{e}_{x}$ and $\overline{e_{x}}$ are the lowest and highest investment amounts possible, respectively. We treat $e_{x}$ generically so that, using our earlier example, investment could represent effort in new customer recruitment, and therefore need not be measured in dollars.

Our first assumption is that individual franchise investment costs are increasing at an increasing rate, as would be true if investment costs represented the cost of borrowing. We represent investment costs by the function $C\left(e_{x}\right)$ where

$$
\frac{d C\left(e_{x}\right)}{d e_{x}}>0 \text { and } \frac{d^{2} C\left(e_{x}\right)}{d e_{x}^{2}}>0 .
$$

Equation (1) implicitly assumes that each franchise faces the same investment cost function. The investment cost function increasing at an increasing rate ensures, however, that franchises do not pool their investments in order to get lower total investment costs. Common ownership of multiple franchises for cost reasons can, within the context of our model, be formulated as ownership of a larger franchise-defined as multiple smaller ones. The vector of franchise investment over the range of different franchises is $\mathbf{e}=\left(e_{x}, e_{\backslash x}\right)$, where $e_{x}$ is the investment made by franchise $x$ and $e_{\backslash x}$ is the vector of investments made by franchises other than $x$.

For a given franchise, we use the term own customers to refer to those customers allocated to the franchise's territory and foreign customers to refer to customers allocated outside of the franchise's territory.
Each franchise faces three positive demands that we assume can be continuously differentiated as necessary.

- $D_{D}(x, \mathbf{e})=$ domestic demand: demand from own customers at own franchise,

- $D_{E}(x, \mathbf{e})=$ exported demand: demand from own customers at foreign franchises,

- $D_{I}(x, \mathbf{e})=$ imported demand: demand from foreign customers at own franchise.

The three types of franchise demands are affected by franchise investments. An individual franchisee, having decision rights over certain activities, considers only the effects of those activities when determining level of investment. In our model, the effects of a franchise's activities affect its own customers.

Our second assumption is that a franchise's domestic demand and its exported demand increase due to its own investment, but the magnitude of that increase falls as higher levels of investment are reached, and those demands are not impacted by other franchises' investments. Consistent with that, we assume that a franchise's imported demand is not affected by its own investment but does increase when other franchises make larger investments.

Those assumptions are reflected mathematically in Table 1 and figuratively in Table 2 . The assumptions in (2) and (3) involve demands that depend on a franchise's own customers. For example, investments in customer recruitment yield more own customers but at a decreasing rate. Domestic and exported demands are not directly affected by other franchises' investments because external investments do not have a direct affect on a franchise's own customers. For example, investments in customer recruitment in one franchise do not directly affect customer recruitment in another franchise. Thus, demand that depends on foreign cus-

Table 1 Demand Assumptions

\begin{tabular}{cccc}
\hline Response to & $\begin{array}{c}\text { Magnitude of } \\
\text { Response to } \\
\text { Demand } \\
\text { Own Investment }\end{array}$ & $\begin{array}{c}\text { Response to Investment } \\
\text { Other Investment }\end{array}$ \\
Domestic & $\frac{\partial D_{D}(x, \mathbf{e})}{\partial e_{x}}>0$ & $\frac{\partial^{2} D_{D}(x, \mathbf{e})}{\partial e_{x}^{2}}<0$ & $\frac{\partial D_{D}(x, \mathbf{e})}{\partial e_{\backslash x}}=0$ \\
Exported & $\frac{\partial D_{E}(x, \mathbf{e})}{\partial e_{x}}>0$ & $\frac{\partial^{2} D_{E}(x, \mathbf{e})}{\partial e_{x}^{2}}<0$ & $\frac{\partial D_{E}(x, \mathbf{e})}{\partial e_{\backslash x}}=0$ \\
Imported & $\frac{\partial D_{l}(x, \mathbf{e})}{\partial e_{x}}=0$ & $\mathrm{~N} / \mathrm{A}$ & $\frac{\partial D_{l}(x, \mathbf{e})}{\partial e_{\backslash x}}>0$ \\
\hline
\end{tabular}


BARRIE R. NAULT Mitigating Underinvestment Through an IT-Enabled Organization Form

Table 2 Investment Responses

\begin{tabular}{llcccc}
\hline Investment & & $\begin{array}{c}\text { Customers } \\
\text { Affected }\end{array}$ & & $\begin{array}{c}\text { Increased } \\
\text { Demand }\end{array}$ & $\begin{array}{c}\text { Rate of } \\
\text { Increase }\end{array}$ \\
\hline Own & $\rightarrow$ & Own & $\stackrel{(2)}{\rightarrow}$ & Domestic & Decreasing \\
Own & $\rightarrow$ & Own & $\stackrel{(3)}{\rightarrow}$ & Exported & Decreasing \\
Other & $\rightarrow$ & Foreign & $\stackrel{(4)}{\rightarrow}$ & Imported & $\mathrm{N} / \mathrm{A}$ \\
\hline
\end{tabular}

tomers, imported demand, is not affected by own investment, (4), because own investment only directly affects own customers. Increases in imported demand, however, are due to other franchises' investments, (4), because those investments directly impact the number of foreign customers.

The magnitude of the demand effects are not necessarily the same for all franchises. For example, if $x$ represents the size of the franchise territory population, then we would expect domestic and exported demand to be larger for a larger $x$. Our assumptions do require that all of the demands behave according to the effects specified in (2), (3) and (4).

Referring to the Pacific Price Systems case, a component of investment in customer recruitment is inperson solicitation of the fueling system to prospective customers. Thus, franchise representatives conduct sales visits to potential clients in their territory, with the desired result of increasing their number of own customers and correspondingly increasing domestic and exported demand. Those sales visits do not increase business coming into the territory from outside-imported demand.

Our structure assumes that each franchise has a local monopoly in the franchise network because it has an exclusive territory. We do not exclude local competition, rather we require that implementation of $\mathrm{OoC}$ not decrease demand at the franchise. In reality, demand is likely to increase at the franchise with $\mathrm{OoC}$ because of the additional services the network can provide. Although franchise territory, as used above, has a geographical connotation, that connotation is not necessary for our results. What is necessary is that customers and/or investments are such so that domestic and exported demand for a given franchise are not affected by investments of other franchises.

For our investment analysis we make the additional assumption that customers purchase outside their home territories at a sufficient rate so that the additional profits are adequate to cover the network investment in IT to support OoC. Because IT costs from OoC are incurred by the franchisor rather than the franchisee, IT costs are not an additional factor in our analysis of franchise investment. We return to the issue of IT costs in our discussion of organization form profits.

The main thrust of our results extend to the case where network externalities from the size of the network (e.g., greater availability of fuel stations) could increase demands. Franchise adoption and network externalities are addressed in Nault and Dexter (1994). Our model does not examine cases where supply is constrained by direct limits or by increasing marginal cost of the marketed good. Our example of commercial fueling is consistent with the model. The supply of fuel is, in effect, unlimited at a constant marginal cost to any network of fueling stations. There is no risk in the model, therefore risk propensities play no role.

\section{Franchise Investment}

We believe improved investment incentives from ITenabled $\mathrm{OoC}$ are the source of additional value our refinement of the horizontal network organization has over traditional franchising. Without IT there is no method to efficiently implement the improvement in investment incentives, incentive improvements that result from being able to track own customers' foreign purchases. Performing the required tasks manually would be more costly, less reliable, and in most cases infeasible.

We begin by comparing franchise investment levels in traditional franchising to those that are obtained with OoC. Those franchise investment levels are then compared to first-best investments, investments that would maximize profits for a fully informed integrated firm. In this section's analysis of franchise investment we take the franchises that belong to the network as given. We address the issue of network membership in the next section.

\subsection{Investments in Traditional Franchising}

Profits for franchise $x$ in traditional franchising, $\Pi^{T F}$, consist of the margin received from the franchisor on domestic and imported demand minus the costs of investment,

$$
\Pi^{T F}(x, \mathbf{e})=m\left[D_{D}(x, \mathbf{e})+D_{I}(x, \mathbf{e})\right]-C\left(e_{x}\right),
$$

where $m$ is the margin - the per-unit amount of profit that goes to the franchise, chosen by the franchisor. Solving for the optimal investment level for franchise $x, e_{x}$, results in the franchise's share of marginal return 
from investment being exactly equal to its marginal investment costs. That is equivalent to the first-derivative condition

$$
\frac{\partial \Pi^{T F}(x, \mathbf{e})}{\partial e_{x}}=m \frac{\partial D_{D}(x, \mathbf{e})}{\partial e_{x}}-\frac{d C\left(e_{x}\right)}{d e_{x}}=0,
$$

where the imported demand derivative disappears from (4). In order for profit maximization to occur the margin must be positive. A positive margin ensures that the second derivative is negative so that the profit function has a single peak (concavity) and so that maximum profits are solved by (5). When Eq. (5) for each franchise is simultaneously satisfied for all franchises, then franchise investments are in equilibrium. In that equilibrium each franchise's investment is a function of the margin, $e_{x}(m)$, and together those investments give a vector of equilibrium investments as a function of the margin, $\mathbf{e}(m)$.

\subsection{Investments Under OoC}

With OoC, foreign transactions occur when customers owned by a franchise in one territory make purchases in other territories. IT enables the owning franchise to actually make the sale and then transfer part of the proceeds to the foreign franchise. That is, the franchise that owns the customer bills the customer. The IT tracks the local franchise making a sale in another franchise's territory. For foreign transactions the franchise that owns the customer makes a transfer to the serving franchise. A given franchise's profit function with $\mathrm{OoC}, \Pi^{\mathrm{OoC}}$, is the margin on domestic demand, the margin less the transfer on exported demand, and the transfer on imported demand, minus the investment costs:

$$
\begin{aligned}
\Pi^{\mathrm{OoC}}(x, \mathbf{e})= & m D_{D}(x, \mathbf{e})+[m-t] D_{E}(x, \mathbf{e}) \\
& +t D_{I}(x, \mathbf{e})-C\left(e_{x}\right),
\end{aligned}
$$

where $t$ is the transfer - the per-unit amount of profit that goes from the owning franchise to the serving franchise. The franchisor chooses both the margin and the transfer. We consider transfers that range between zero and the margin, $0 \leq t \leq m$. In contrast to the profit function for franchises in traditional franchising, IT allows for exported demand to be included. For an individual franchise, equating marginal return and marginal costs through the first-order condition for profit maximization when choosing investments, again using (4) to eliminate the marginal return from im- ported demand, produces

$$
\begin{aligned}
\frac{\partial \Pi^{\mathrm{OoC}}(x, \mathbf{e})}{\partial e_{x}}= & m \frac{\partial D_{D}(x, \mathbf{e})}{\partial e_{x}}+[m-t] \frac{\partial D_{E}(x, \mathbf{e})}{\partial e_{x}} \\
& -\frac{d C\left(e_{x}\right)}{d e_{x}}=0
\end{aligned}
$$

If the transfer is no greater than the margin, then the concavity condition sufficient to ensure profits are maximized by the above equation is satisfied from (1), (2), and (3),

$$
\begin{aligned}
& \frac{\partial^{2} \Pi^{\mathrm{OoC}}(x, \mathbf{e})}{\partial e_{x}^{2}} \\
& =m \frac{\partial^{2} D_{D}(x, \mathbf{e})}{\partial e_{x}^{2}}+[m-t] \frac{\partial^{2} D_{E}(x, \mathbf{e})}{\partial e_{x}^{2}} \\
& \quad-\frac{d^{2} C\left(e_{x}\right)}{d e_{x}^{2}}<0 .
\end{aligned}
$$

If we allow the transfer to be larger than the margin, then the second-derivative condition that ensures concavity, (7), may not hold, and therefore (6) may not result in the maximum profits for a franchise. Similar to traditional franchising, the set of first-order conditions defined by (6) for all franchises defines the equilibrium vector of investments, but now as a function of both the margin and the transfer, e $(m, t)$. It is worth noting that if the marginal returns from exported demand, the second term in (6), is small, then, comparing the profit maximizing conditions under traditional franchising and $\mathrm{OoC},(5)$ and (6), OoC has little effect.

When the margin is completely transferred to the serving franchise, $t=m$, investments and profits are identical to traditional franchising. Now, consider what happens when the transfer is less than the margin, giving $t<m$. We can explicitly define an equation that implicitly defines the franchises' equilibrium investments, $\mathbf{e}(m, t)$. Using (6), let the equation

$$
\beta(x, m, t, \mathbf{e})=\frac{\partial \Pi^{\mathrm{OoC}}(x, \mathbf{e})}{\partial e_{x}}=0
$$

implicitly define e $(m, t)$. From (7) and (3) respectively, we can determine the partial effects

$$
\frac{\partial \beta(x, m, t, \mathbf{e})}{\partial e_{x}}=\frac{\partial^{2} \Pi^{\mathrm{OoC}}(x, \mathbf{e})}{\partial e_{x}^{2}}<0
$$


and

$$
\frac{\partial \beta(x, m, t, \mathbf{e})}{\partial t}=-\frac{\partial D_{E}(x, \mathbf{e})}{\partial e_{x}}<0 .
$$

Using the implicit function rule, ${ }^{2}$ we can determine the change in franchise investment that results from a change in the transfer,

$$
\frac{\partial e_{x}(m, t)}{\partial t}<0
$$

meaning franchise investment is inversely related to the transfer-an increase in the transfer reduces investment and vice-versa. That condition holds for all the franchises, that is, all of the $e_{x}(m, t)$ in $\mathbf{e}(m, t)$. As compared to traditional franchising, in which the transfer is equal to the margin, under OoC the transfer from the owning franchise to the serving franchise is less than the margin, which means that individual franchise investment increases for all franchises. Thus, investments are higher with OoC.

Consider the point of view of a particular franchise. When the margin on exported demand is lost from transferring the entire margin, as it is with traditional franchising, the franchise has no incentive to create exported demand through additional investment in own customers. When the transfer is reduced however, as under $\mathrm{OoC}$, part of the margin on exported demand accrues to the owning franchise, giving the owning franchise greater marginal returns on investment from own customers. Those higher marginal returns provide the owning franchise an incentive to increase its investment. Therefore, IT and OoC put additional incentives in place that increase franchise investment.

\subsection{First-Best Investments}

Although OoC can increase franchise investment, when the transfer is less than the margin the equilibrium levels of investment under OoC fall short of first-best investments in an integrated firm. In an integrated firm the head office has access to local expertise and can mandate investment levels to outlets. Because customers are owned by individual outlets, profit maximization for the firm can be obtained by optimizing profits at each outlet separately. Profits from a particular outlet $x, \Pi^{F B}$, are the total per-unit profit received on a purchase (i.e., price premium), $p$, times demand, less the costs of investment:

$$
\Pi^{F B}(x, \mathbf{e})=p\left[D_{D}(x, \mathbf{e})+D_{E}(x, \mathbf{e})\right]-C\left(e_{x}\right),
$$

where the price premium received by the integrated firm is no less than the margin, $p \geq m$. The price premium at Pacific Pride, for example, is the amount the customer pays for fuel less the cost of providing the fuel. The condition equating marginal revenue to marginal cost which defines the optimal first-best levels of investment at the outlet is

$$
\begin{aligned}
\frac{\partial \Pi^{F B}(x, \mathbf{e})}{\partial e_{x}}= & p\left[\frac{\partial D_{D}(x, \mathbf{e})}{\partial e_{x}}+\frac{\partial D_{E}(x, \mathbf{e})}{\partial e_{x}}\right] \\
& -\frac{d C\left(e_{x}\right)}{d e_{x}}=0 .
\end{aligned}
$$

Marginal profit for the outlet declines with increased investment so, again, the concavity condition is satisfied. Condition (10) holds for all of the franchises and implicitly defines optimal first-best investments.

To compare optimal first-best investments to investments obtained under $\mathrm{OoC}$, we can use our equation that implicitly defines investment as a function of the margin and the transfer, (8). Using (8), from (2) and (4),

$$
\frac{\partial \beta(x, m, t, e)}{\partial m}=\frac{\partial D_{D}(x, \mathbf{e})}{\partial e_{x}}+\frac{\partial D_{E}(x, \mathbf{e})}{\partial e_{x}}>0
$$

and using the implicit function rule as before, we find that franchise investment under $\mathrm{OoC}$ increases as the margin is increased, $\left[\partial e_{x}(m, t)\right] / \partial m>0$. The intuition is simple: a larger margin increases marginal revenue from investment for the franchise, without affecting the marginal cost. Thus, relative to first-best investments, any margin that is less than the full price premium received by the franchisor (under traditional franchising or OoC) yields underinvestment.

\subsection{Underinvestment}

Therefore, under OoC and in traditional franchising, as the margin is increased, greater levels of investment are obtained. Investments also increase under $\mathrm{OoC}$ as the transfer is decreased. Comparing the profit maximizing conditions under OoC and first-best, (6) and (10), first-best levels of investment occur when the margin is the full price premium, $p=m$, and the transfer is zero, $t=0$, which is again intuitive: Reduction of the margin or positive levels of the transfer remove profits from the owning franchise, lowering their returns from investment and causing the franchises to underinvest in equilibrium. 
At some level of generality that underinvestment is consistent with the Mathewson and Winter (1984) result on advertising spillovers: because a proportion of advertising messages from one outlet increases demands at other outlets, the levels of advertising chosen by franchises are lower than would otherwise be optimal. It is also consistent with Brickley and Dark (1987), who observed that when part of the benefits from advertising go to other units, a franchise has reduced incentives to advertise. The specific mechanism underlying our underinvestment result is that owning franchises are not fully rewarded for purchases their own customers make from other outlets.

Imported demand is the source of the free rider problem, that is, foreign franchises benefit from efforts by owning franchises. There may well be franchises with little domestic and exported demand and little response of those demands to increased investment. In equilibrium such franchises will invest little or nothing. That is a natural outcome of the model.

However, the presence of OoC-that is, identification of customers with individual franchises, perfect monitoring of customer purchases, and transfers between franchises - mitigates the problem of franchise underinvestment because it more fully rewards actions over which the franchise has control. Hence, IT allows franchise actions to be tied to the specific outcomes that result from these actions. Using wording similar to Rubin (1978), giving a franchise a larger share of the profits from its actions in that part of the operation it can most efficiently control, creates greater incentives for it to be efficient.

\section{Organizational Form Profits}

\subsection{Volume}

We begin by studying the total volume of purchases across franchises assuming that all existing franchisees remain in the network. If total volume can be increased without changing the price premium, then total profits increase. Because total imports across franchises must equal total exports, in calculating total volume it does not matter which is included. Therefore, we can write the total purchase volume with $\mathrm{OoC}$ as domestic demand plus imported demand, aggregated over all franchises:

$$
\begin{aligned}
& Q(\mathbf{e}(m, t)) \\
& \quad=\int_{\underline{x}}^{\bar{x}}\left[D_{D}(x, \mathbf{e}(m, t))+D_{I}(x, \mathbf{e}(m, t))\right] f(x) d x .
\end{aligned}
$$

The equation for total volume in traditional franchising is identical except that the vector of investments would depend on the margin only, e $(m)$. If the transfer is equal to the margin, $t=m$, then OoC has no effect on total volume. For $\mathrm{OoC}$ to have an effect means only part of the margin is transferred from the owning franchise (which is paid by the customer) to the serving franchise, that is, $t<m$.

The effect of a change in the transfer on total volume is equal to the change in domestic and imported demand due to the change in investment that results from the change in the transfer. That is described by

$$
\begin{aligned}
& \frac{d Q(\mathbf{e}(m, t))}{d t} \\
& =\left[\int_{\underline{x}}^{\bar{x}} \frac{\partial D_{D}(x, \mathbf{e}(m, t))}{\partial e_{x}} f(x) d x\right] \frac{\partial e_{x}(m, t)}{\partial t} \\
& \quad+\left[\int_{\underline{x}}^{\bar{x}} \frac{\partial D_{I}(x, \mathbf{e}(m, t))}{\partial e_{\backslash x}} f(x) d x\right] \frac{\partial e_{\backslash x}(m, t)}{\partial t} .
\end{aligned}
$$

From the result of Eq. (9) we know that increasing the transfer will decrease investments. From our assumptions in (2) and (3) a decrease in investments will decrease the demands and therefore total volume will decrease. The reverse is also true. Thus, the change in total volume is inversely related to a change in the transfer. That outcome occurs directly through the investment incentive covered in the prior section: A decreased transfer, for example, increases return on investment for the owning franchise, thereby increasing investment in equilibrium. The increased investment generates more customers, increasing both domestic and foreign (imported/exported) demands.

In contrast, franchise investments increase as the margin received from the franchisor increases, as we found earlier. The effect of a change in the margin on total volume follows the same form as the effect of a change in the transfer on total volume, except that the effect on investment is reversed. Thus, an increase in the margin increases total volume, and vice versa. As a result, total volume is maximized under first-best investments where the margin is expanded to the full price premium. 


\subsection{Profitability}

We now examine the impact of $\mathrm{OoC}$ on organizational form profits. If the membership of the franchise network is constant, then the impact of OoC on franchisor profits can be seen immediately from the franchisor's profit maximization problem. Franchisor profits are the price premium less the margin given to the franchise, times total volume. The transfer does not play a role in the contribution margin obtained by the franchisor. In traditional franchising, the franchisor selects only the margin and attempts to choose a margin to maximize profits, $\Psi(m)$, or,

$$
\max _{m} \Psi(m)=\max _{m}[[p-m] Q(\mathbf{e}(m))] .
$$

With OoC, the franchisor determines both the margin and the transfer to maximize profits, $\Psi(m, t)$, where only the transfer affects the volume,

$$
\max _{m, t} \Psi(m, t)=\max _{m, t}[[p-m] Q(\mathbf{e}(m, t))] .
$$

If the transfer is set equal to the margin, then only the margin needs to be determined, and profits from the two organization forms are identical. Directly from our conclusion that a change in the transfer has the reverse effect on total volume (also described by (11)), we find that any decrease in the transfer relative to the margin increases total volume, which increases profits. In other words, given a price premium $p$ and a margin $m$, employing $\mathrm{OoC}$ and setting the transfer lower than the margin, $t<m$, results in increased investment by the franchises, and, therefore, higher total volume and higher total profits in the network.

With OoC the franchisor is more profitable because it could set the margin at the same level as it would in traditional franchising and the resulting higher total volume and higher total profits, as described above, would increase franchisor profits. Moreover, because that setting increases total network profits, joint profits between the franchisor and franchisees are increased. Therefore, given constant membership, our refinement of the horizontal network organization can always produce higher joint profits, meaning that this organizational form can successfully accommodate franchisor objectives or joint objectives without changing the manner in which franchises make investment decisions.

\subsection{Membership}

Although we have assumed that the franchisor can mandate a change from traditional franchising to OoC, it may be that some franchisees are made worse off under $\mathrm{OoC}$ and would prefer other investment options. That is, because franchisees have countless other options available including other franchises in the same industry organized in the traditional way, lower profits for them under $\mathrm{OoC}$ may cause them to leave the network.

An example can illustrate the point. Consider a franchise with large imported demand but few own customers - a truck stop located along a major highway but away from any cities. Such a franchise could be worse off under $\mathrm{OoC}$ than under traditional franchising because its reduced revenue from imported demand (the transfer rather than the margin) under OoC may not be offset by increased revenue from exported demand. If the franchise has an alternative such as becoming an independent truck stop or joining another traditional franchise operation that could yield higher profits than under $\mathrm{OoC}$, then the franchise will leave the network. Therefore, increases in franchisor profits or in joint profits from increased investment is not alone sufficient for our refinement of the horizontal network organization to be more profitable because those profits depend on network membership.

We consider two scenarios. First, if franchise profits under $\mathrm{OoC}$ are larger than the next best alternative for each franchise, then all the franchises will remain in the network. Because OoC unambiguously increases franchisor profits and can increase joint profits of the franchisor and franchises, then the profitability of our refinement of the horizontal network organization is enhanced by that application of IT.

Second, suppose some franchises have alternatives that are more profitable than OoC. Because they were part of the traditional franchise network, their profits under other alternatives must have been lower than under traditional franchising. We have shown that $\mathrm{OoC}$ can increase joint profits of the franchisor and franchisees as compared with traditional franchising. If the franchisor can implement lump-sum payments to redistribute profits to the franchises, then each franchise can be made at least as profitable under OoC as it would be with traditional franchising and the franchisor can be made more profitable. Hence, if lumpsum payments are possible, IT-enabled OoC can increase the profitability of our refinement of the horizontal network organization over that of traditional franchising.

\subsection{IT Costs}

IT costs in each organizational form have not yet been included in the analysis. We believe IT costs in our 
refinement of the horizontal network organization are likely to be lower than IT costs needed to obtain first-best investment levels, that is, optimal investments in an integrated firm. First-best investments require monitoring both transactions and franchise investment. The monitoring system for the latter may be quite costly, for example, a salesperson call reporting system. Although $\mathrm{OoC}$ requires database matching, transaction processing and funds transfers for transactions (as would be needed in an integrated firm), OoC relies on incentives rather than on monitoring to promote investment. Under traditional franchising IT may also be required to monitor transactions and to transfer funds between the franchisor and individual franchises. There is, however, no requirement for matching customers to franchises nor for transfers between franchises. Thus, IT costs in traditional franchising are likely to be lower than in our refinement of the horizontal network organization. Because the IT applications required to support $\mathrm{OoC}$ are not particularly sophisticated, we believe the benefits from increased investment will most often exceed the additional IT costs.

Nevertheless, should the magnitude of additional IT costs be a factor, then their effects on our analysis depend on how they are partitioned. IT costs can be divided into two components. The first is a nondecreasing function of the number of transactions essentially a marginal transaction cost for the franchisor. Inclusion of that cost in our model would affect the price premium $p$ received by the franchisor under OoC, thereby affecting the optimal choices of the margin and transfer made by the franchisor in $\Psi(m, t)$. A large marginal transaction cost could lower the margin chosen under $\mathrm{OoC}$, relative to the margin chosen in traditional franchising. Because increases in the margin yield increases in franchise investment, our central results concerning $\mathrm{OoC}$ increasing franchise investment may no longer hold in the presence of sufficiently large marginal transaction costs. It is worth noting, however, that advances in IT have yielded marginal transaction costs that are near zero. At Pacific Pride, for example, the central computer polls each franchise daily to download transactions, and that telecommunication connection is completed in seconds, which means there may be no additional costs for more transactions. Similarly, costs at Pacific Pride are relatively insensitive to increases in the number of transactions processed.

The second IT cost component is one that is independent of the number of transactions and is lumpy, hardware and software costs for example. Inclusion of that cost in our model would directly affect the profitability of the franchisor through the addition of a fixed cost. Should the franchisor decide to distribute that cost through a lump-sum fee, or require that franchisees bear the fixed costs of converting their franchise to enable OoC, then the franchisees' profitability under OoC relative to their next best alternative may be affected negatively. Franchisees may defect from the network, causing a membership problem that would lower the profitability of OoC to less than it would have been under traditional franchising. The degree to which lumpy IT costs compromise OoC depends on the additional joint profit obtained under OoC over traditional franchising relative to the fixed IT costs, and on the next best alternatives facing franchisees. It is worth noting, however, that the fixed IT costs are one-time costs as opposed to increased profits which continue over time.

\section{Conclusion}

In franchise arrangements, incentives for individual franchise investment are crucial because of the horizontal investment externality - investment by any one franchise affects other franchises. The main problem is that individual franchises underinvest because they do not account for the benefits accruing to other franchises from their investment. We have shown that the underinvestment problem can be eliminated, in part, through a horizontal network organization implementing IT-enabled OoC. We have also shown that the franchisor receives increased profits, and the franchisor and franchisees can obtain increased joint profits, demonstrating that the application of IT can make that new organizational form more attractive. The transfer structure is robust to changes in which of the franchises bill the customer on foreign transactions. There is no loss of generality by having the serving franchise bill the customer and making a transfer to the owning franchise. The results continue to hold. That is important because there are likely to be cases where it is more convenient for the serving franchise to bill the customer.

Our model provides a concrete illustration of how IT can enable new organizational forms through refinements of old ones. Our refinement of the horizontal network organization requires the implementation of OoC to account for interdependencies between network members. Implementation of $\mathrm{OoC}$ requires three items. First, individual customers must be identified with individual franchises. Second, transactions by customers at foreign franchises must be perfectly monitored and verifiable. Third, transfers between franchises must be based on these foreign transactions. 
The commercial fueling example described in the introduction illustrates the IT-enabled structure: a database is maintained matching customers to franchises, automated teller-like machines keep perfect information on transactions across the network of franchises, and transfers are exchanged between franchises based on foreign customer purchases. IT is critical because it is too costly to implement regimes like $\mathrm{OoC}$ without IT.

The ability to implement sharing rules through IT that impact investment incentives has the potential to revolutionize organizational forms. Expanding on our model, as long as there are no territory overlaps, OoC can be implemented in a modified form between horizontal network organizations. For example, an HMO (health maintenance organization) can have agreements with HMOs in other regions to cover travelling customers. Other examples include agreements to honor country club or health club memberships for visiting members from other regions, and possibly trading frequent flyer miles among airlines in non-competing market segments. As such, virtual horizontal network organizations can be created.

That is consistent with the theme that coordination costs between economic agents can be reduced by IT through greater efficiencies in information gathering, simplified contracting and more effective protection against risks of opportunistic behavior-in essence, decreasing transaction costs (Williamson 1981). It is well known that IT-enhanced control systems can improve monitoring. What is novel about our approach is that we demonstrate that IT can also be used to improve incentives.

Many industrial markets either already employ or could employ IT-enabled OoC. Distributors in bulk fuel, for example, often serve clients that purchase fuel for geographically dispersed depots. Because servicing the geographically dispersed depots from one distributor is inefficient, transfers are arranged between the distributor that owns the client and those distributors that serve the dispersed depots. Though not strictly franchise operations, professional service firms (e.g., law, engineering, and accounting firms) can also employ OoC. When dealing with a conglomerated client, the firm's branch located closest to the conglomerate's head office owns the client. Branches in other locations perform functions in their respective areas-for example, local audits. The billing arrangement usually rewards the branch that "owns" the head office and the local branches.

OoC has limitations that determine when implementation is profitable. First, OoC is not feasible if cus- tomers do not want to be identified with a home territory or when they purchase. Second, it is not effective if franchise profits from customers purchasing away from home are so low that they do not provide an incentive for additional franchise investment. Those low profits can occur as a result of small profit margins or because the propensity to purchase away from home is small. Many common retail franchise structures, for example McDonalds or Burger King, cannot employ OoC because of those reasons. In those examples, it is not feasible to identify customers as being owned by individual franchises because of low customer compliance, and transfers may have little effect because of small profit margins. Third, increases in franchise investment and the resulting additions to joint profits may not cover the IT costs required to implement OoC.

However, we argue that profitable implementation of IT-enabled OoC is possible in most industrial markets, that is, in markets where the customers are firms and an ongoing relationship exists between the customer and the organization. Implementation in retail markets in which there are repeat purchases and customers are identified, for example hotel chains and insurance companies, may also be profitable. Investment there may relate to the quality of the good or service provided. OoC may also play a role in making other IT applications that exhibit horizontal externalities more profitable. In electronic markets, having more participants provides greater liquidity, and liquidity is the most important criterion in selecting between alternative markets (Bakos 1991, Clemons and Weber 1996). Electronic data interchange is also described as having potential positive externalities. Interesting areas for future research include examining how electronic data interchange and use of the Internet may facilitate a further enhanced $\mathrm{OoC}$, perhaps across industries, and the impact of integrating OoC into franchise termination laws. ${ }^{3}$

\section{Acknowledgments}

The author is grateful to Victoria Mitchell, Richard Wolfe, Al Dexter, Lane Daley, Richard Townell, Ron Weber, the Senior Editor and two anonymous Reviewers for their suggestions and guidance. Part of the research was done while the author was visiting the University of British Columbia. Partial support was provided by the Social Science and Humanities Research Council of Canada and the NOVA Corporation of Alberta.

\footnotetext{
Endnotes

${ }^{1}$ Our results on local investment also apply to national investment in a context where there are both local and national investments and where local and national investments are complementary. Details are available upon request.
} 
${ }^{2}$ The implicit function rule allows us to examine the effect of a change in one variable on another variable when the variable whose effect we wish to study cannot be isolated on one side of the equation. It requires that we implicitly define the desired function (e.g., $\mathbf{e}(m, t))$ by setting an equation that contains all the variables to zero (e.g., $\beta(x, m, t, \mathbf{e})=0$, that is, the condition that marginal returns to investment equal the marginal costs). Intuitively, that can be thought of as a balanced equation. Then, by changing one variable in a particular direction, we can determine which direction the other variable has to move in order to keep the equation balanced (at zero). The implicit function rule is extremely useful because we can often determine the effects of one variable on another in situations where it is so complex, or the formulation is sufficiently general, that we are unable to isolate one variable or the other. In the case of determining the effect of a change in the transfer on investment, the implicit function rule holds that

$$
\frac{\partial e_{x}(m, t)}{\partial t}=-\frac{\frac{\partial \beta(x, m, t, \mathbf{e})}{\partial t}}{\frac{\partial \beta(x, m, t, \mathbf{e})}{\partial e_{x}}},
$$

which means that we can determine this effect merely by signing two partial derivatives of the balanced equation rather than having to algebraically isolate $e_{x}$ or $t$.

${ }^{3}$ Franchise underinvestment, and its mitigation, also follow directly from Hart and Moore's (1990) property rights results. If an additional franchise is Pareto beneficial to other franchises and if the horizontal investment externality holds, then the franchise organization has complementary franchise investment at the margin, superadditivity in franchises, and marginal superadditivity in franchise investment. Those assumptions are shown to lead directly to underinvestment under any ownership structure. In our franchise environment ITenabled OoC allows more of the increased productivity from investment to be captured, thereby partially alleviating the causes of underinvestment.

\section{References}

Bakos, J. Y. (1991), "Information Links and Electronic Marketplaces: The Role of Interorganizational Information Systems in Vertical Markets," Journal of Management Information Systems, $8,2,31-52$.

$\rightarrow$ Brickley, J. A. and F. H. Dark (1987), "The Choice of Organizational Form: The Case of Franchising," Journal of Financial Economics, 18, 401-420.

Clemons, E. K. and B. W. Weber (1996), "Alternative Securities Trading Systems: Tests and Regulatory Implications of the
Adoption of Technology," Information Systems Research, 7, 2 (June), 163-188.

Hart, O. and J. Moore (1990), "Property Rights and the Nature of the Firm," Journal of Political Economy, 98, 6 (December), $1119-1158$

HBS Case Services (1985, 1986, 1988), "Pacific Pride Commercial Fueling System (A), (B), (C),” 9-186-014, 9-186-015, 9-188-084, Harvard Business School, Boston, MA.

Katz, M. L. (1989), "Vertical Contractual Relations," Chapter 11 in Handbook of Industrial Organization, Volume 1, R. Schmalensee and R. D. Willig (Eds.), Elsevier Science Publishers B. V., 655-721.

$\rightarrow$ Mathewson, G. F. and R. A. Winter, (1984), "An Economic Theory of Vertical Restraints," The Rand Journal of Economics, 15, 1 (Spring), 27-38.

Miles, R. E. and C. C. Snow (1992), "Causes of Failure in Network Organizations," California Management Review, Summer, 53-72.

Nault, B. R. and A. S. Dexter (1992), "Interorganizational Information Systems in Industrial Markets," Chapter 14 in Strategic Information Technology Management: Perspectives on Organizational Growth and Competitive Advantage, R. Banker, R. J. Kauffman and M. Mahmood (Eds.), Idea Group Publishing, 297-316.

$\longrightarrow$ and _ (1994), "Adoption, Transfers and Incentives in a Franchise Network with Positive Externalities," Marketing Science, 13,4 (Fall), 412-423.

and __ (1995), "Added Value and Pricing with Information Technology,” Management Information Systems Quarterly, 19, 4 (December), 449-463.

Norton, W. S. (1988), "An Empirical Look at Franchising as an Organizational Form,” Journal of Business, 61, 2, 197-218.

Rogers, E. M. (1983), Diffusion of Innovations, New York: Free Press.

Rubin, P. S. (1978), "The Theory of the Firm and the Structure of the Franchise Contract," Journal of Law and Economics, 21 (April), 223-233.

Scott-Morton, M. (1991), The Corporation of the 1990's, Oxford, England: Oxford University Press.

Snow, C. C., R. E. Miles and H. J. Coleman Jr. (1992), "Managing 21st Century Organizations," Organizational Dynamics, Winter, 5-20.

$\rightarrow$ Thorelli, H. B. (1986), "Networks: Between Markets and Hierarchies," Strategic Management Journal, 7, 37-51.

$\rightarrow$ Williamson, O. E. (1981), "The Economics of Organization: The Transaction Cost Approach," American Journal of Sociology, 87, 3, 548-577.

Accepted by Robert Zmud; received August 1994. This paper has been with the author for four revisions. 